\title{
PRINCIPAIS CARACTERÍSTICAS DO SISTEMA DE REMUNERAÇÃO VARIÁVEL NO CHOQUE DE GESTÃO EM MINAS GERAIS: O ACORDO DE RESULTADOS E O PRÊMIO POR PRODUTIVIDADE
} MAIN CHARACTERISTICS OF THE PERFORMANCE-RELATED PAY SYSTEM IN MINAS GERAIS STATE GOVERNMENT: THE RESULTS AGREEMENT AND THE PRODUCTIVITY PRIZE

Mário Teixeira Reis Neto

Universidade Fumec

Luis Otávio Milagres de Assis

Fundação Getulio Vargas
Recebido em: 05/10/2009

Aprovado em: 19/03/2010

\section{RESUMO}

A implantação de sistemas de remuneração variável tem sido uma importante estratégia de melhoria do serviço público na experiência internacional. Entretanto, sua penetração no Brasil é incipiente. A experiência do governo estadual de Minas Gerais, chamada de "choque de gestão", é paradigmática, pois coloca em funcionamento o que é, atualmente, o maior programa de remuneração variável da administração pública brasileira. Nessa experiência, cada órgão público assinou um acordo de resultados (contrato de gestão baseado em indicadores de desempenho). Vinculado à avaliação dos contratos, foi implantado o prêmio por produtividade, que, a partir de 2008, foi estendido a todo o Poder Executivo estadual. O presente artigo descreve e analisa as características do sistema de remuneração variável implementado em Minas Gerais, comparando-o a experiências internacionais. Fez-se uma revisão da literatura referente à remuneração variável por desempenho, analisando as tendências e lições aprendidas com a experiência internacional e relacionando-as ao caso estudado. Discutiu-se, também, a relação entre esse modelo de remuneração e outras estratégias de reforma presentes no choque de gestão. Concluiu-se que o modelo mineiro é compatível, em grande medida, às boas práticas internacionais. Entre os dilemas enfrentados, destaca-se o risco da universalização da premiação, que pode induzir um comportamento oportunista e conservador na definição de metas, transformando o prêmio num simples 14ํㅜ salário.

Palavras-chave: choque de gestão, acordo de resultados, contratualização de resultados, remuneração variável, prêmio por produtividade. 


\section{ABSTRACT}

The implementation of performance-related pay systems has been an important strategy related to the improvement of the public sector based on international experiences. However, its dissemination in Brazil is inceptive. The experience of Minas Gerais state government, is a reference, since it is now running the major performance-related pay program in public administration in the country. In Minas Gerais state, each organization signed a Results Agreement (performance contract based on performance indicators). A Productivity Prize was implemented, along with the evaluation of those contracts, reaching all servants since 2008. This article describes and analyses the characteristics of the performance-related pay system implemented in Minas Gerais state in comparison to international experiences. Related literature is reviewed, focusing on trends and lessons learned worldwide, drawing a parallel to the case studied. The relation between this pay system and other reform strategies applied in Minas Gerais state is also analyzed. The conclusion is that the system studied is similar to international practices. A dilemma that this experience is facing is the risk of a comprehensive implementation, which may be an incentive to opportunist behavior related to a conservative goal-setting, turning the Productive Prize into a mere additional salary.

Keywords: results agreement, performance contracting, performance-related pay, productivity prize.

\section{INTRODUÇÃO}

O debate sobre a reforma e a modernização do Estado frequentemente aborda as ferramentas e os métodos que têm sido utilizados com sucesso no setor privado. No caso da remuneração variável no setor público, a literatura científica nacional mostra a ausência de experiências práticas no Brasil, na medida em que apresenta um debate incipiente sobre o tema. No âmbito internacional, são frequentes os debates acadêmicos sobre o uso dessa estratégia como parte do processo de modernização do setor público em diversos países. Assim, dois estudos tiveram papel de destaque na elaboração do presente trabalho. O primeiro, produzido pela Organização para a Cooperação e Desenvolvimento Econômico (OCDE, 2005), analisou e sistematizou as características e as boas práticas observadas em sistemas de remuneração variável no setor público. O segundo foi desenvolvido por Perry, Engbers \& Jun (2009), que investigaram 57 importantes trabalhos sobre o tema na literatura internacional e sistematizaram tendências e lições aprendidas.

Na experiência do choque de gestão realizado no Estado de Minas Gerais, Brasil, os conceitos e as práticas da gestão pública por resultados estão articulados a um sistema de remuneração variável ainda inédito no setor público brasileiro, do ponto de vista de sua abrangência. Cada órgão do Poder Executivo estadual assinou um contrato de gestão baseado em indicadores de desempenho, chamado acordo de resultados, caracterizado pelo pagamento de bônus anuais aos servidores públicos, segundo o desempenho (resultado atingido) avaliado por uma comissão. De acordo com dados oficiais da Secretaria de Planejamento do Estado, em 2008, o sistema já abrangia 99,7\% dos servidores em atividade no Poder Executivo.

Diante da relevância do caso mineiro, marcada por sua abrangência e pela duração de seis anos, o presente artigo tem o objetivo de descrevê-lo, tendo em vista as características básicas de sistemas similares existentes no exterior. Faz-se uma relação entre esse sistema e outras estratégias de modernização presentes do choque de gestão mineiro e ainda se busca responder à seguinte questão: em quais aspectos o modelo implantado em Minas Gerais se aproxima ou se distancia das experiências internacionais de remuneração variável no setor público?

\section{A REMUNERAÇÃO VARIÁVEL NO SERVIÇO PÚBLICO}

Pfeffer e colaboradores (O’ReILly III \& Pfeffer, 2000; Pfeffer, 1999; Pfeffer \& Veiga, 1999) afirmaram que a maneira como as organizações gerenciam seu pessoal é a real e verdadeira fonte de vantagem competitiva. Os referidos autores estudaram como desenvolver e manter essa vantagem em uma 
economia baseada no conhecimento, e afirmaram que mais importante e difícil do que atrair e reter pessoas fantásticas é criar culturas e sistemas em que elas possam realmente usar seu talento. Para isso, é preciso gerenciar ações que levem quase todos a produzir resultados extraordinários. Nas organizações de sucesso, isso ocorre por meio de práticas focadas nos empregados, tais como remuneração, orientação para a equipe e compartilhamento de informações.

Segundo Lawler III (2000), talvez o mais forte argumento para a criação de um sistema de remuneração por desempenho esteja no fato de que o dinheiro é a única commodity. Ele é relativamente fácil de distribuir, é valorizado pela maioria dos indivíduos, pode ser distribuído facilmente e existe em toda sociedade organizada. Além disso, é algo que todos esperam receber quando trabalham para uma organização, exceto em casos altruístas, voluntários e filantrópicos. Na verdade, uma organização que aufere resultados não consegue operar sem distribuir dinheiro a seus empregados. Essa distribuição não deve ser baseada, nem completamente nem parcialmente, no valor do capital humano. Pesquisas indicam que a distribuição de pelo menos parte do dinheiro segundo o desempenho contribui para a eficácia da organização. Especificamente nessas condições, ele parece ser justo e motivador.

No setor público, alguns sistemas de remuneração variável foram implantados para carreiras específicas, com grande poder de articulação, que barganharam gratificações especiais. Apesar de ser sinônimo de modernidade que as carreiras dos servidores tivessem em sua composição remuneratória uma parcela financeira variável por desempenho, não houve a implantação e a consolidação de sistemas consistentes de avaliação de resultados que a sustentassem. O que houve, em muitos casos, foi a incorporação dessa parcela variável ao salário, fazendo com que discussões para negociação desse tipo de gratificação fossem o prenúncio de aumento do salário fixo (PACHECO, 2009).

No cenário internacional, muito tem sido escrito sobre experiências dessa natureza em diversos países. Assim, cabe apresentar uma revisão sobre alguns estudos relevantes para o contexto do presente trabalho.

\subsection{Constatações e recomendações da Organização para a Cooperação e Desenvolvimento Econômico (OCDE)}

O Policy Brief, publicado pela Secretaria-Geral da OCDE (2005) como orientação técnica aos países-membros dessa comunidade, analisa de forma ampla os programas de remuneração variável em funcionamento no setor público. Seu objetivo foi destacar as melhores práticas e as lições aprendidas em diversas experiências internacionais. Dentre 30 países que compõem a OCDE, mais de dois terços já utilizam programas de remuneração variável por desempenho, ao menos em parte do serviço público (OCDE, 2005: 2). Porém, poucos países (Inglaterra, Dinamarca, Nova Zelândia, Finlândia, Coreia e Suíça) utilizaram, de forma abrangente, o pagamento por desempenho para todo o serviço público. Nos outros casos, a abrangência varia bastante: parte dos países utilizou-o apenas no nível gerencial; outros, apenas em setores específicos do governo. A aplicação e o design de sistemas de remuneração variável por desempenho (performancerelated pay - PRP) variam bastante. Observam-se, porém, duas características comuns: (a) recentemente, sistemas de PRP deixaram de ser exclusivos dos níveis gerenciais e passaram a abranger níveis não gerenciais; (b) diversos países estão incentivando a PRP com abordagem coletiva (desempenho de equipes/setores), em substituição à abordagem individual (desempenho individual) (OCDE, 2005).

Ainda segundo a OCDE (2005), o uso dos bônus periódicos tem crescido em detrimento de gratificações vinculadas ao salário, já que aqueles são gerenciados com maior flexibilidade, não gerando crescimento fixo da folha de pessoal. Outro ponto importante é a proporção da remuneração variável comparada à fixa. Tal característica também muda entre os diversos países, mas a parcela variável é geralmente modesta diante da remuneração total. Em regra, no caso de gratificações mensais, a parcela variável por desempenho não supera $5 \%$ do valor total da remuneração mensal. No caso dos bônus, esse valor é um pouco maior, mas não ultrapassa $10 \%$ do equivalente mensal ao salário fixo dos servidores públicos. Para o nível gerencial, essa parcela é um pouco maior, chegando a $20 \%$ do montante global.

O período avaliatório dos programas internacionais de PRP é, geralmente, de um ano. Em um pri- 
meiro momento, são identificados objetivos prioritários e, ao final, avalia-se o resultado alcançado. Os critérios de avaliação geralmente incluem os seguintes itens: (a) resultados predeterminados para objetivos (não necessariamente quantificados); (b) competências técnicas e interpessoais; (c) trabalho em equipe; (d) liderança e competências gerenciais (OCDE, 2005: 4).

Uma dificuldade permanentemente percebida na experiência internacional refere-se à mensuração do desempenho. Esquemas altamente formais e detalhados têm se mostrado malsucedidos. Um desafio sempre presente é diferenciar o desempenho de cada pessoa do desempenho médio satisfatório de um grupo. Nos Estados Unidos, a maioria dos programas de remuneração variável nos anos 1980 classificou o desempenho de mais de 95\% dos gerentes como altamente satisfatório. Em função dessas dificuldades, duas tendências se observam: (a) o uso de sistemas menos detalhados, com uma escala de três pontos em vez de dez ou 20; (b) o uso de cotas que definem proporções máximas para aqueles que são considerados os melhores e os piores (OCDE, 2005: 4).

De acordo com a OCDE (2005), as lições e os aprendizados da experiência de programas de PRP são os seguintes:

- o design deve levar em consideração a cultura do país e da organização. O equilíbrio entre fatores individuais e coletivos na remuneração é chave. Esquemas focados em equipes parecem ter efeitos mais positivos do que os focados em aspectos individuais;

- a remuneração variável é parte de um sistema mais amplo. O sucesso do programa depende mais da qualidade do processo de mensuração do desempenho do que do peso monetário da premiação;

- problemas de implementação devem ser antecipados, devendo ser preparados os servidores e as chefias;

- o programa deve estar vinculado a uma gestão de pessoas fundada na delegação. É mais fácil vincular objetivos individuais aos da organização se há certa autonomia para os gerentes atuarem;

- a importância e o significado da PRP não devem ser superestimados. Seu impacto na motivação dos servidores é secundário;
- os programas devem ser aplicados em ambientes onde as relações de trabalho sejam fundadas na confiança;

- acima de tudo, a PRP deve ser utilizada como incentivo e estímulo a uma transformação mais abrangente.

É consenso na literatura internacional a baixa efetividade de programas de PRP no setor público. Muitos servidores não enxergam a remuneração variável por desempenho como incentivo. A maioria, especialmente aqueles que não ocupam postos gerenciais, considera o salário fixo e seu valor, comparado ao mercado, como mais importantes do que a remuneração variável por desempenho em si. Para eles, a natureza e o conteúdo do emprego e as possibilidades de desenvolvimento na carreira foram identificados como os principais fatores de incentivo. A remuneração variável por desempenho no setor público fracassa em motivar a grande maioria dos servidores, independentemente de sua configuração (OCDE, 2005: 6).

Entretanto, a Organização para o Desenvolvimento e a Cooperação Econômica apontou que, apesar das limitações, os programas de PRP continuam sendo importantes para a melhoria e a mudança da gestão pública. A introdução da remuneração variável pode não melhorar o resultado e o desempenho, mas as mudanças necessárias para implementá-la podem gerar esse efeito. O impacto no aumento da motivação do empregado é pequeno e não gera, por si, aumento no desempenho. No entanto, diversos efeitos derivados, que surgem com a implantação de sistemas de remuneração variável, podem gerar efeitos positivos na melhoria dos resultados. Com o funcionamento desses sistemas torna-se necessário que o gerente e sua equipe definam, negociem, acompanhem e mensurem dados sobre indicadores e metas. Os resultados tornam-se, naturalmente, tema de discussão entre a chefia e os subordinados. O alinhamento dos esforços dos servidores em torno das prioridades estabelecidas é um desses efeitos derivados. Além disso, a definição de metas proporciona um senso de cooperação quando elas são coletivas. Tudo isso, porém, só contribui para o aumento do desempenho quando existe um ambiente adequado para a implantação da PRP, com confiança e transparência no sistema de avaliação. A existência desses 
elementos contribui para que os efeitos derivados proporcionem aumento no desempenho e melhoria efetiva nos resultados. Esses argumentos são sustentados pela OCDE (2005), assim como por Perry, Engbers \& Jun (2009), como se observará na próxima seção. A Figura 1 sintetiza essa lógica.

Ainda corroborando esse argumento, um importante estudo publicado por Marsden (2004) avaliou o impacto da remuneração variável no serviço público britânico nos anos 1990 e concluiu que a PRP foi um instrumento fundamental para incentivar e facilitar a renegociação de padrões de desempenho entre gerentes e subordinados. O fortalecimento de um processo constante de negociação e debate sobre o desempenho foi considerado o impacto mais significativo da implantação desse sistema no setor público da Grã-Bretanha. Ele contribuiu para ampliar a clareza e o conhecimento sobre os objetivos e resultados almejados.

\subsection{Novas análises sobre a remuneração variável no serviço público internacional}

Coerentemente com o trabalho da OCDE, Perry, Engbers \& Jun (2009) fizeram uma robusta revisão analítica de 57 estudos publicados entre 1977 e
2008 sobre a implantação de sistemas de remuneração variável no setor público em diversos países. O objetivo foi analisar a eficácia e a efetividade dos programas de PRP observados em todos os estudos publicados. Dentre as constatações, foi destacado que "a remuneração variável por desempenho no setor público falha na sua promessa" (Perry, Engbers \& Jun, 2009: 43), no sentido de que não se mostra, em regra, um incentivo para a maioria dos colaboradores. Os autores identificaram sete lições/aprendizados que sintetizam as conclusões dos 57 estudos analisados.

1. A PRP tem, geralmente, falhado em induzir mudanças na percepção dos empregados, necessárias para alterar a motivação, ou seja, a parcela variável não consegue, em geral, promover motivação adicional dos empregados. Entretanto, foram identificados bons resultados quando as metas eram claras, e a recompensa e o suporte à implantação do programa de remuneração variável eram adequados. Alguns pesquisadores encontraram realidades em que os empregados percebiam baixa relação entre desempenho e recompensa, enquanto outros verificaram descrença em relação à possibilidade real de

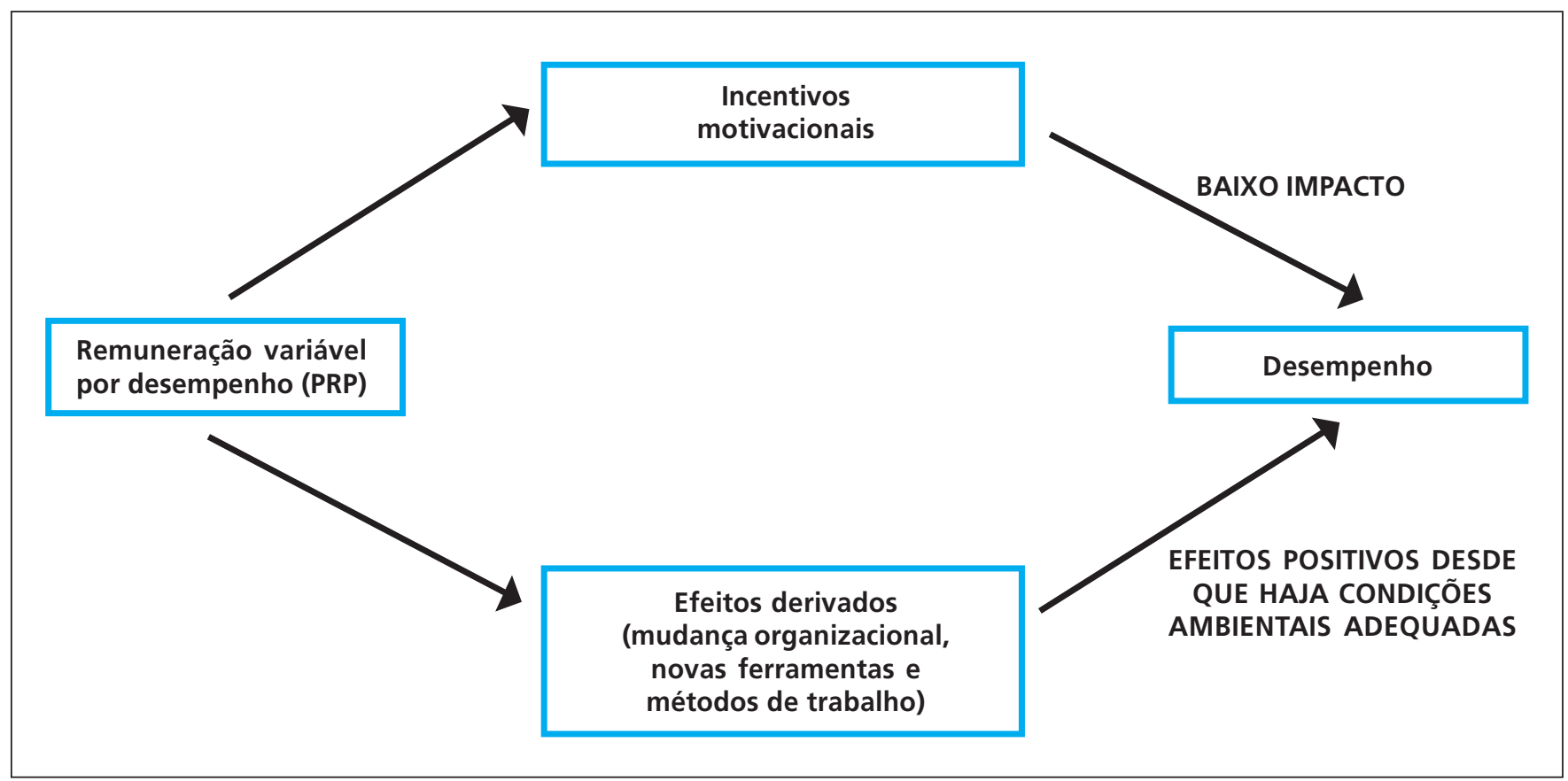

Figura 1: Ganhos e impactos de programas de PRP Fonte: OCDE (2005: 6). 
receber pagamento superior. Outros empregados entendiam que o incentivo financeiro era pouco representativo para ser valorizado. Contudo, quando se foca em 14 estudos de alta qualidade sobre PRP (com experimentos e amostras aleatórios, além de análises de séries temporais), os resultados são contraditórios. Quatro são claramente negativos, outros quatro não permitem tirar qualquer conclusão e cinco são favoráveis à PRP, no sentido de que ela contribuiu para a melhoria nos resultados. Esses cinco estudos bem-sucedidos foram realizados em organizações da área de saúde e utilizaram sistemas de pagamento por unidade produzida (piece-rate compensation programs).

2. Uma variedade de fatores contextuais, como o nível de confiança e um consistente sistema de avaliação, influencia na efetividade dos programas de PRP. Um fator, entretanto, se destaca: o tipo de política pública envolvida. Experiências de PRP na área de saúde são altamente positivas; entretanto, na área de regulação e no setor financeiro, são negativas. Ficam no meio termo os resultados nas áreas de educação e segurança pública.

3. Os programas de remuneração variável parecem ter maior efeito nos níveis operacionais da organização em que as tarefas são menos ambíguas e os resultados, mais concretos e mensuráveis, contradizendo a premissa de que seriam mais efetivos nos níveis gerenciais. É necessário ressaltar que muitos empregados consideram a PRP injusta. O que está por atrás dessa percepção, em geral, é o baixo nível de confiança no ambiente de trabalho, a falta de transparência na avaliação e a falta de credibilidade da liderança.

4. As falhas na implementação não constituem a única razão do insucesso de programas de PRP. Três aspectos institucionais são determinantes: transparência - o sucesso (ou o fracasso) dos programas depende da percepção, por parte dos empregados, de que o sistema é justo, transparente e não político; em segundo lugar, a questão orçamentária, já que o montante monetário necessário é significativo e fica condicionado às nuances do comportamento da receita; em terceiro lugar, a visão externa sobre o pagamento da premiação, porque parte da sociedade pode considerar ilegítima uma recompensa além do salário, em troca de resultados superiores.

5. Sistemas de remuneração variável com relações diretas entre produção (resultados) e desempenho são mais bem-sucedidos do que aqueles baseados no julgamento das chefias.

6. Não é recomendável adotar um sistema de remuneração variável simplesmente porque todos o estão fazendo. É necessário considerar as contingências e os fatores específicos, adaptando o sistema de maneira que ele faça sentido e seja efetivo na organização.

7. Há muito espaço para novas pesquisas. Quatro campos se destacam: (a) Quais as influências específicas do salário-base e da parcela variável no desempenho? Como avaliar o peso de cada componente? (b) De que forma e por que os incentivos vinculados a objetivos coletivos são mais bem-sucedidos? (c) Quais características de design na modelagem dos programas são mais efetivas? (d) Como avaliar e quão efetivos são os benefícios indiretos advindos da implementação de programas de PRP?

Finalmente, vale complementar que dois dos textos de referência internacional (OCDE, 2005; PERRY, EngBers \& Jun, 2009) tratam do tema da remuneração variável por desempenho (performancerelated pay) não necessariamente baseada apenas em resultados, mas também em outros critérios de avaliação do desempenho.

\section{METODOLOGIA}

O presente trabalho foi elaborado a partir de uma pesquisa aplicada, essencialmente qualitativa, exploratória, focada na observação participante, realizada entre janeiro de 2007 e novembro de 2009 na Diretoria Central de Modernização da Gestão da Secretaria de Estado de Planejamento e Gestão de Minas Gerais (Seplag-MG), cuja função era coordenar a política de contratualização de resultados e de remuneração variável dos servidores. A observação participante contemplou os acordos de resultados do governo do Estado no que se refere aos seguintes aspectos: (a) debates e entrevistas 
realizados com atores-chave do governo de Minas Gerais - dirigentes e servidores de carreira - quando da revisão metodológica do sistema mineiro, ocorrida em 2007; (b) reuniões de discussão de metas entre a equipe técnica de cada órgão e a Seplag; (c) reuniões gerenciais coordenadas pelo vice-governador e por outros dirigentes do governo estadual; (d) seminários e eventos de divulgação para os servidores públicos sobre a elaboração do acordo de resultados e discussão sobre o prêmio por produtividade; (e) reuniões internas na Seplag sobre a concepção e a melhoria do modelo; ( $f$ ) reuniões das comissões de avaliação dos acordos de resultados. Também foram examinados os documentos e manuais técnicos sobre o processo de contratualização dos resultados e os relatórios sobre o desempenho de cada órgão.

Com base na metodologia utilizada, a apresentação e as análises dos dados pesquisados são influenciadas pela interpretação dos autores, guiados pelo problema de pesquisa e pelos objetivos inicialmente estabelecidos. Assim, o foco foi analisar o modelo mineiro sob a ótica de um programa de remuneração variável; entretanto, o acordo de resultados poderia, também, ser analisado sob a ótica da contratualização de resultados, que se apoia em outro marco teórico (que não é objeto desta investigação).

\section{O CHOQUE DE GESTÃO E O SISTEMA MINEIRO DE REMUNERAÇÃO VARIÁVEL}

O acordo de resultados e o prêmio por produtividade se inserem numa estratégia maior de reforma no setor público em Minas Gerais, conhecida como "choque de gestão". Segundo Lemos (2009), ele é composto por uma combinação de medidas de ajuste estrutural das contas públicas, com iniciativas voltadas para um novo padrão de desenvolvimento, tendo a inovação da gestão como elemento de sustentabilidade. Para Vilhena (2006), o choque de gestão representa um caso de adoção de medidas típicas de reformas de primeira geração (ajuste fiscal) associadas a medidas de reformas de segunda geração (desenvolvimentistas).

Em relação às reformas de segunda geração, Lemos (2009) destacou os três principais movi- mentos do modelo mineiro: (a) revitalização dos instrumentos formais de planejamento, que permitiu definir escolhas estratégicas; (b) concepção de novo arranjo institucional orientado para resultados, baseado na avaliação de desempenho institucional (acordo de resultados) e em formas inovadoras de relacionamento com o setor privado (celebração de parcerias com OSCIPs -organizações da sociedade civil de interesse público e a celebração de PPPs parcerias público-privadas); e (c) estabelecimento de um novo padrão de gestão de pessoas, fundamentado no fortalecimento da capacitação e na avaliação de desempenho.

Dentro da lógica do choque de gestão, em 2003 foi concebida e implementada a política de contratualização de resultados no Governo do Estado de Minas Gerais. No contexto da implementação da chamada administração pública gerencial, a contratualização de resultados é entendida como uma importante estratégia de melhoria da eficiência e da efetividade do setor público (BrAsIL, 1995). A estratégia contratual, baseada em pactuação e avaliação de resultados, é considerada uma das três práticas mais relevantes, do ponto de vista de seu impacto nas estratégias de reforma do serviço público (JANN \& REICHARD, 2002).

O modelo é operacionalizado a partir da assinatura de um acordo de resultados (contrato de gestão) entre cada dirigente de órgão e o governador, no qual a organização assume compromissos a serem entregues para a sociedade. Esse contrato estabelece indicadores e metas que a organização se compromete a alcançar. Em contrapartida, são concedidas autonomias gerenciais e a possibilidade de recebimento de prêmio por produtividade aos servidores públicos, em caso de resultados satisfatórios em relação às metas pactuadas.

Os indicadores e as metas, que são o conteúdo principal dos acordos de resultados, são orientados principalmente pelo Plano Mineiro de Desenvolvimento Integrado (PMDI), que é o planejamento de longo prazo, e pelos 57 projetos estruturadores, que são os projetos prioritários do PPAG (Plano Plurianual de Ação Governamental). Para compreender a estrutura do funcionamento desse modelo, é necessária uma pequena revisão dos instrumentos de gestão aplicados no Executivo estadual. 


\subsection{O papel do acordo de resultados no sistema de gestão em Minas Gerais}

Todo o planejamento governamental se baseia no Plano Mineiro de Desenvolvimento Integrado PDMI, que foi recentemente revisado com metas de resultado (outcomes) e objetivos estratégicos até 2023 (Minas Gerais, 2007). Como resultado, tem-se um planejamento com opções estratégicas que estão, de fato, sendo referência para as ações dos órgãos e entidades do governo estadual. O PMDI foi organizado por 11 áreas de resultado (educação de qualidade, vida saudável, redução da pobreza e inclusão produtiva, entre outras), sendo cada uma delas um núcleo focal de esforços e ações prioritárias, possuindo um conjunto de objetivos e um rol de projetos. Assim, foi definida uma carteira de 57 projetos chamados de estruturadores, que sintetizam os principais esforços de governo e recebem tratamento especial, dos pontos de vista da destinação de recursos e do gerenciamento.

Cada um desses projetos é acompanhado sistematicamente por um escritório de projetos (Geraes), atualmente composto por, aproximadamente, 16 técnicos formados pela Escola de Governo da
Fundação João Pinheiro. Para cada projeto, é nomeado um gerente e é feito um detalhamento anual, com metas, marcos e cronograma, assim como os recursos financeiros necessários. A cada mês é produzido um relatório (status report), mostrando o desempenho de cada ação do projeto. Os resultados e a evolução dos cronogramas são supervisionados mensalmente pela cúpula de governo. Sob a liderança presente do vice-governador, secretários de Estado e dirigentes são constantemente chamados a prestar contas sobre a evolução das metas e dos resultados previstos em cada projeto, nas chamadas reuniões de comitê.

Para organizar essa lógica de acompanhamento sistemático de resultados pelo vice-governador, foi criado o Programa Estado para Resultados, que se constitui num corpo de técnicos que monitora os resultados e apoia a evolução dos projetos, atuando nos problemas e obstáculos identificados nas reuniões de acompanhamento. $O$ detalhamento do funcionamento desse modelo de governança foi descrito por Silveira (2008). A Figura 2 sintetiza a lógica do planejamento e oferece como exemplo uma área de resultado.

\section{EXEMPLO DE ÁREA DE RESULTADO: EDUCAÇÃO DE QUALIDADE}

\section{Objetivos estratégicos:}

Promover um salto na escolaridade média da população, formada em um sistema eficiente, com altos níveis de eqüida de e orientado por padrões internacionais de custo e qualidade;

Reduzir as disparidades regiona is de aprendizado em Minas Gerais.

\section{RESULTADOS FINALÍSTICOS}

- Aumentar o percentual de alunos do 3 . ano da rede estadual com nível recomendado de leitura de $72 \%$ (2008) para $81 \%$ (2009) e 90\% (2010). - Reduzir a distorção idade/série no ensino fundamental da rede estadual de $24 \%$ (2007) para $17 \%$ (2009) e $13 \%$ (2010).

- Aumentar a taxa de conclusão do ensino médio de $42 \%$ (2006) para $53 \%$ (2008) e $58 \%$ (2009).
PROJETOS ESTRUTURADORES

○ Novos padrões de gestão e atendimento da Educação Básica

o Escola em tem po integral

- Sistema de avaliação da qualidade do ensino e das escolas

o Desempenho e qualificação dos professores
CRONOGRAMA B

CRONOGRAMA A

CRONOGRAMA C

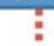

CRONOGRAMA D

Figura 2: Exemplo da área de resultado educação de qualidade Fonte: dados da pesquisa (2009). 
Considerando a existência do gerenciamento intensivo dos projetos estruturadores, o sistema de contratualização de resultados em Minas Gerais foi concebido de forma a se alimentar desse sistema, com o objetivo de fortalecer a qualidade dos resultados pactuados no contrato. O acordo de resultados tem como um de seus principais componentes o estabelecimento de um pacto sobre as metas de execução dos cronogramas dos 57 projetos estruturadores.

O contrato mineiro integra as ferramentas de gestão atualmente em funcionamento no Poder Executivo estadual. As metas pactuadas em cada acordo de resultado são baseadas no PMDI e têm como importante componente a taxa de execução dos projetos estruturadores. Assim, a função do contrato de gestão é mobilizar os servidores em torno das metas e dos cronogramas dos 57 projetos, já que, uma vez pactuados no acordo de resultados, o cumprimento desses cronogramas é fundamental para o recebimento da premiação por produtividade.

Os 57 projetos estruturadores não têm o objetivo de priorizar os esforços de todos os setores dos 63 órgãos do Executivo estadual. Embora sintetizem as grandes opções estratégicas e as principais entregas do governo (principais obras, ações mais importantes da área de saúde, educação etc.), não há intenção de que alcancem (estabelecendo foco e prioridade) toda a máquina pública do Executivo. Analisandose o detalhamento dos projetos estruturadores, observa-se que apenas 33 dos 63 órgãos e entidades possuem ações específicas em um ou mais dos 57 projetos. E, mesmo considerando que um órgão possui ações específicas sob sua responsabilidade, isso não significa que elas sejam suficientes para orientar e definir foco para todos os setores e para os servidores dessas unidades. Tomando como exemplo três das maiores secretarias (Educação, Saúde e Defesa Social), responsáveis por serviços públicos prestados diretamente ao cidadão, é difícil dizer que os servidores e gerentes de unidades, nos diversos municípios (escolas, hospitais, unidades prisionais), enxerguem, nos cro- nogramas dos projetos, orientações sobre suas prioridades.

É nesse espaço que se localiza a segunda e mais importante função do acordo de resultados no sistema de gestão estadual. Além de orientar o orçamento e o esforço do governo em torno das opções estratégicas, é necessário orientar para resultados cada setor, cada unidade gerencial, em torno de metas de desempenho alinhadas à estratégia. A definição de indicadores e metas para cada unidade gerencial, requisito para a assinatura do acordo de resultados, cumpre esse papel. A consolidação de uma cultura em que o foco nos resultados de cada unidade se sobreponha à centralidade nos procedimentos depende, fundamentalmente, da capacidade da unidade gerencial de enxergar seus fins e possuir indicadores de desempenho e métodos de mensurar e acompanhar os resultados.

As ferramentas utilizadas no Executivo mineiro (gerenciamento de projetos e contratualização de resultados) integram-se e potencializam-se mutuamente. Os contratos ficam mais robustos já que têm como um dos componentes principais os projetos estruturadores. Assim, tais projetos tornamse prioritários na medida em que as recompensas estão vinculadas ao seu cumprimento. A Figura 3 sintetiza a lógica do funcionamento das práticas de gestão no governo do Estado.

Se, por um lado, o acompanhamento sistemático dos resultados dos projetos estruturadores ocupa a cúpula de governo e prioriza os problemas a serem enfrentados, a pactuação de metas entre cada dirigente de órgão (ou entidade) e os gerentes das

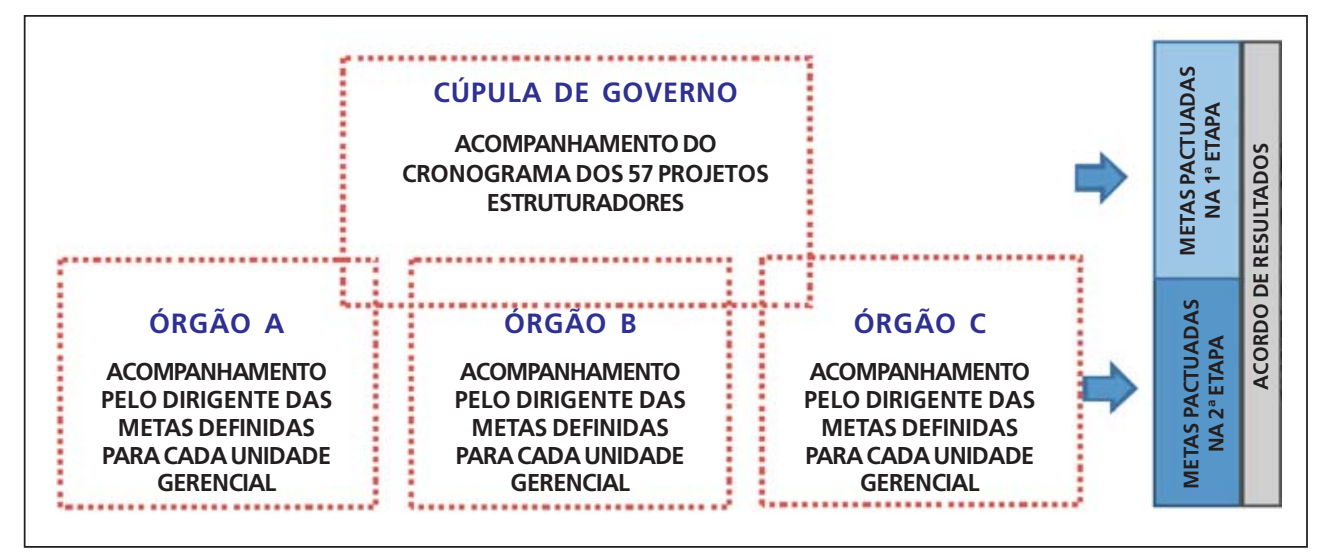

Figura 3: Práticas de gerenciamento induzidas pelos métodos implantados em Minas Gerais Fonte: dados da pesquisa (2009). 
unidades gerenciais (superintendências, escolas, hospitais, unidades prisionais) oferece condições para um segundo nível de gestão por resultados. O dirigente de cada órgão pode utilizar-se dos indicadores e das metas definidos para acompanhar sistematicamente os resultados de cada setor de seu órgão. Assim, o acordo de resultados contribui para o fortalecimento da gestão estratégica na cúpula e em cada órgão público do Estado.

\section{2. $O$ acordo de resultados e a primeira lógica de premiação (2003-2007)}

Desde o início da implementação do choque de gestão houve alterações significativas na remuneração dos servidores. A Emenda à Constituição n. $57 / 2003$ deu fim às figuras dos adicionais por tempo de serviço (biênios, quinquênios e trintenários) e ao apostilamento, benefícios que independiam de produtividade, resultados e eficiência. Em contrapartida, foi instituída uma política de remuneração variável, com a concessão de vantagens decorrentes de avaliação de desempenho institucional e individual. Essas vantagens constituíram-se no prêmio por produtividade e no adicional de desempenho (ADE). Poucos servidores, entretanto, optaram pelo modelo do $A D E$, que, em setembro de 2008 , era pago a apenas 4.497 servidores, em um universo de mais de 300 mil em atividade. Dessa forma, o sistema mais relevante de remuneração variável implementado em Minas Gerais é o prêmio por produtividade, tanto em relação ao volume de recursos investidos e ao número de servidores atingidos quanto ao alinhamento com o planejamento estratégico governamental.

O prêmio por produtividade é uma recompensa financeira que poderá ser concedida aos servidores dos órgãos e entidades do Poder Executivo de Minas Gerais que firmarem o acordo de resultados e alcançarem resultados satisfatórios em seu cumprimento. Embora pertençam a duas modalidades distintas de políticas de gestão pública, o prêmio por produtividade (política de remuneração variável) e o acordo de resultados (política de contratualização de resultados) foram concebidos de forma vinculada pela legislação e integram a mesma lógica.

A experiência de contratualização de resultados e premiação por produtividade em Minas Gerais já atinge seis anos de implementação. Em 2003, foi aprovada a Lei Estadual n. 14.694, regulamentada pelo Decreto n. 43.675 e por alterações posteriores, formatando o marco legal do modelo mineiro. Foram especificados por esse arcabouço legal conceitos, procedimentos de elaboração e formalização do contrato, além da sistemática e dos critérios de avaliação das metas e das regras para distribuição do prêmio aos servidores. A avaliação dos acordos de resultados é feita por comissões de acompanhamento e avaliação (CAA), cujos membros têm seus nomes publicados no Diário Oficial. Tais comissões verificam o grau de cumprimento das metas e atribuem notas. Em caso de nota igual ou superior a 70\%, o desempenho era considerado satisfatório e estaria cumprida a primeira precondição para o pagamento do prêmio.

Nessa primeira fase do arcabouço legal, havia a previsão de duas possíveis fontes de recursos para viabilizar a premiação. Considerado satisfatório o desempenho, o órgão poderia pleitear o pagamento por produtividade por meio de uma delas: (a) economia com despesas correntes: nessa modalidade, até 1/3 do montante economizado por cada órgão ao longo do ano poderia ser utilizado para o pagamento do prêmio; e (b) ampliação real de receitas: nessa modalidade, a fonte para pagamento do prêmio era a diferença entre a arrecadação obtida em um ano em relação ao exercício anterior. Esse valor tem como limites máximos até 10\% de receitas diretamente arrecadadas pelos órgãos e, ainda, até 3\% da receita proveniente de impostos e taxas.

Outro aspecto a ser destacado como característica desse primeiro marco legal foi sua vinculação à avaliação de desempenho individual (ADI). O cálculo individual para o pagamento da premiação era composto conforme apresentado na Figura 4:

Sob essa legislação, de 2003 a 2007 foi pago um valor total de $R \$ 202$ milhões. Nesse período, observa-se que apenas $R \$ 15$ dos $R \$ 202$ milhões tiveram origem no prêmio por economia de despesas. A maior parte do valor pago, nesse período - quase R\$180 dos R\$202 milhões -, foi destinada a servidores da Secretaria de Estado da Fazenda, tendo como base a modalidade "ampliação de receita". Em suma, nesse primeiro momento (20032007), as duas modalidades de fonte de recursos para as premiações previstas pela legislação eram viáveis para pequena parte dos 63 órgãos e entida- 


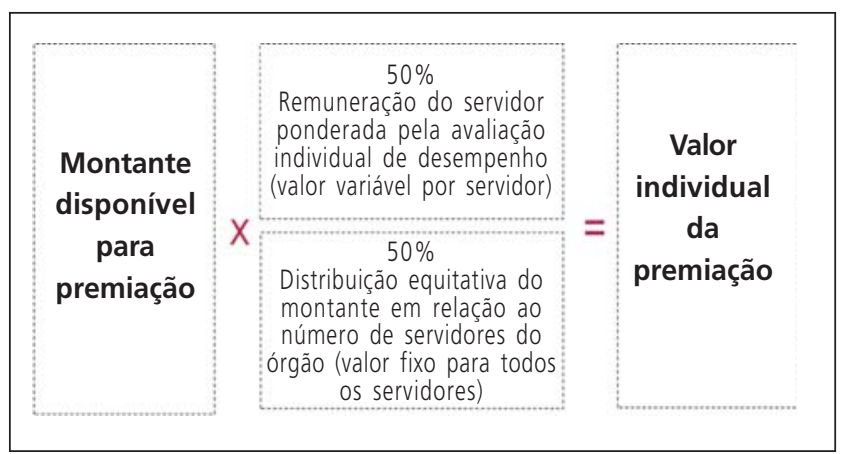

Figura 4: Cálculo da premiação por servidor

Fonte: dados da pesquisa (2009).

des do Executivo. Poucos órgãos arrecadavam e poderiam optar pela modalidade de ampliação e, ainda, poucos se enquadravam na modalidade de economia de despesas correntes.

É interessante retomar aqui o sentido e o papel da remuneração variável, no que se refere à necessidade de clara relação entre a recompensa e o resultado. Nessa primeira fase da legislação, quando se obtinha na avaliação um mínimo de $70 \%$ de cumprimento do contrato, havia o pagamento da premiação. Ou todos os servidores do órgão ganhavam ou ninguém ganhava, não sendo o valor pago proporcional à nota obtida no acordo de resultados. Tanto um resultado de $75 \%$ quanto um de $98 \%$ eram premiados da mesma forma. Além disso, todos recebiam o mesmo prêmio, sem diferenciação interna de contribuição para o alcance das metas.

Essas regras geraram uma consequência indesejável para um sistema de remuneração variável: a baixa relação percebida pelos servidores entre seu desempenho no dia a dia e sua premiação. Dois foram os motivos dessa percepção. Em primeiro lugar, a premiação se baseava na lógica do tudo ou nada, não sendo proporcional ao desempenho. Em segundo lugar, ainda nesse primeiro período, o valor da premiação tinha vinculação direta com a nota da avaliação de desempenho individual (avaliação de competências). Esse vínculo não é saudável, na medida em que a possibilidade de pagamento do prêmio por produtividade de forma diretamente proporcional ao resultado da avaliação individual distorce esse último instrumento, gerando avaliações artificialmente positivas, com o objetivo de aumentar a remuneração. Por esses motivos, percebeu-se, no decorrer da experiência, a neces- sidade de se reformular a lógica da premiação por produtividade.

Em 2006, havia 22 órgãos com acordos vigentes, envolvendo aproximadamente $39 \%$ do Poder Executivo estadual. Cabe destacar que, nesse primeiro momento, a lógica de assinar um acordo de resultados era a da adesão. Cada órgão ou entidade poderia propor ao governo a pactuação, que era analisada por uma equipe técnica antes da assinatura.

\subsection{O acordo de resultados e a segunda lógica de premiação (2007 em diante)}

Em 2007, iniciou-se um movimento de revisão da metodologia do acordo de resultados e da lógica de premiação por produtividade, que culminou em nova legislação. Segundo a equipe que elaborou o novo marco legal, os objetivos da revisão foram os seguintes: (a) aumentar a percepção do servidor de que a premiação era função do desempenho alcançado; (b) estabelecer na legislação uma nova modalidade de prêmio para que todos os órgãos tivessem uma fonte de pagamento que gerasse um prêmio razoável. Assim, foi criada a Lei n. 17.600/ 2008, que extinguiu a modalidade de economia de despesas e criou uma modalidade com base na receita corrente líquida. Esse fato alterou a lógica de que cada órgão deveria buscar uma fonte de recursos para pagamento de seu prêmio e criou uma fonte universal: um percentual da receita corrente líquida do Estado poderia ser revertido em prêmio por produtividade. Foi criado, assim, um incentivo que possibilitou a que todos os órgãos e entidades premiassem, sem depender de orçamento próprio.

Por outro lado, era ainda necessário fortalecer a vinculação entre a premiação e a produtividade no trabalho. Para isso, a nova legislação trouxe uma revisão geral da metodologia do acordo de resultados e da lógica do cálculo individual do prêmio. 0 acordo de resultados passou a ser estabelecido em duas etapas. Na primeira, o foco é sintetizar os objetivos gerais da política e da estratégia por meio dos resultados finalísticos, de taxas de execução de projetos estruturadores, de metas da agenda setorial, de indicadores e de racionalização dos gastos. Os resultados desejados são pactuados entre o governador do Estado e o dirigente máximo de cada órgão ou entidade. Na segunda etapa, o diri- 
gente faz um desdobramento desses resultados com seus servidores, conforme pode ser visto no exemplo apresentado no Quadro 1.

Com a identificação de metas mais próximas ao dia a dia do servidor, ficou mais evidente a contribuição de cada equipe para a estratégia. No novo modelo, a premiação passou a ser proporcional à nota alcançada no acordo de resultados. Para cada meta pactuada na segunda etapa, é atribuída uma nota, segundo o que foi realizado, ou seja, cada uma das 4.739 equipes que pactuaram metas específicas obtém uma nota pelo desempenho individual. Existe ainda a nota atribuída à primeira etapa, que é pertinente ao desempenho do sistema como um todo (saúde, educação, cultura etc.). Por exemplo, para que as equipes (escolas) tenham direito ao prêmio, o sistema de educação como um todo teria de atingir $60 \%$ na nota do que foi pactuado na primeira etapa.
Foi criado ainda um mecanismo especial para se evitar que as equipes tenham notas muito altas, enquanto o desempenho do sistema como um todo seja ruim. Por esse mecanismo, a nota média das equipes (segunda etapa) não pode ser superior à nota global do setor de governo (primeira etapa). Caso isso ocorra, as notas das equipes são proporcionalmente reduzidas até que sua média fique abaixo da nota global do setor.

Finalmente, a remuneração pelo desempenho de cada servidor é calculada segundo o critério estabelecido na Figura 5.

Vale ressaltar que a Figura 5 reflete duas características relevantes nesse segundo marco legal (após 2007). Em primeiro lugar, a desvinculação com a avaliação de desempenho individual (ADI). A nota obtida pelo servidor na ADI é utilizada para fins de progressão e promoção na carreira, mas não tem relação com o valor recebido na premiação por

Quadro 1: Exemplo de indicadores de cada etapa do acordo de resultados

\begin{tabular}{|c|c|c|}
\hline Meio Ambiente & Saúde & Transportes e Logística \\
\hline $\begin{array}{l}\text { Metas de impacto para a sociedade } \\
\text { 1a Etapa do Acordo de Resultados } \\
\text { - Aumentar o percentual do } \\
\text { território mineiro com cobertura } \\
\text { vegetal nativa } \\
\text { - Tempo médio para a deliberação } \\
\text { sobre licenciamentos ambientais }\end{array}$ & $\begin{array}{l}\text { Metas de impacto para a sociedade } \\
\text { 1a Etapa do Acordo de Resultados } \\
\text { - Reduzir o índice de mortalidade infantil } \\
\text { - Ampliar o percentual de moradias com } \\
\text { acesso a rede de esgoto } \\
\text { - Reduzir o percentual de internações por } \\
\text { condições sensíveis à atenção } \\
\text { ambulatorial }\end{array}$ & $\begin{array}{l}\text { Metas de impacto para a sociedade } \\
\text { 1a Etapa do Acordo de Resultados } \\
\text { - Aumentar o percentual da malha } \\
\text { rodoviária estadual em boas } \\
\text { condições de conservação } \\
\text { - Aumentar o número de municípios } \\
\text { com acesso por meio de vias } \\
\text { asfaltadas }\end{array}$ \\
\hline $\begin{array}{l}\text { Metas desdobradas para as equipes } \\
\text { 2a Etapa do Acordo de Resultados } \\
\text { - Área com cobertura vegetal } \\
\text { nativa ampliada por regional do } \\
\text { IEF } \\
\text { - Tempo médio de licenciamento } \\
\text { em cada uma das } \\
\text { Superintendências Regionais de } \\
\text { Meio Ambiente }\end{array}$ & $\begin{array}{l}\text { Metas desdobradas para as equipes } \\
\text { 2a Etapa do Acordo de Resultados } \\
\text { - Taxa de infecção hospitalar e taxa de } \\
\text { mortalidade em UTI neonatal aferida em } \\
\text { cada unidade hospitalar } \\
\text { - Número de doações de múltiplos órgãos } \\
\text { efetuados pelo MG Transplantes } \\
\text { - Número de coletas de sangue realizadas } \\
\text { por cada regional da HEMOMINAS. }\end{array}$ & $\begin{array}{l}\text { Metas desdobradas para as equipes } \\
\text { 2a Etapa do Acordo de Resultados } \\
\text { - Percentual da malha em boas } \\
\text { condições por regional do DER } \\
\text { - Número de abordagens a veículos } \\
\text { (fiscalização) por regional do DER } \\
\text { - Aditamento de prazo em contratos } \\
\text { (atrasos na execução) verificados } \\
\text { em cada regional do DER. }\end{array}$ \\
\hline
\end{tabular}

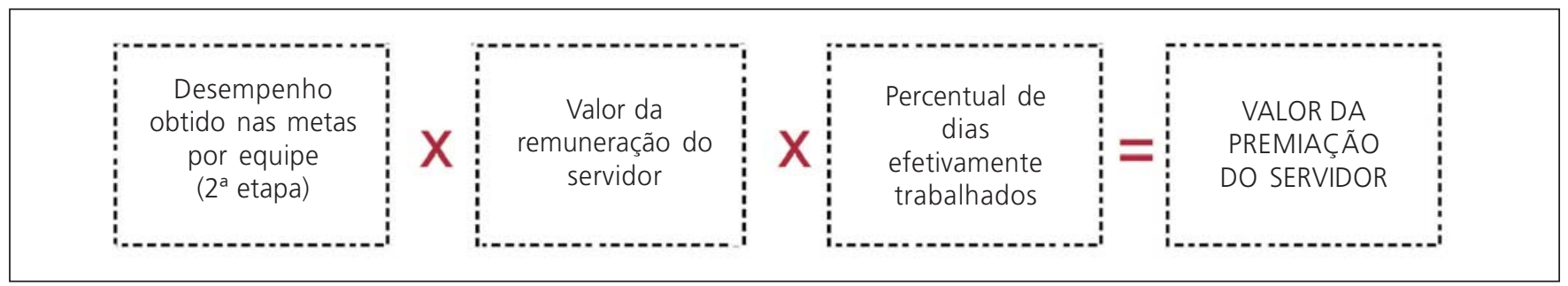

Figura 5: Cálculo da premiação baseado na nova legislação Fonte: dados da pesquisa (2009). 
produtividade. Em segundo lugar, o prêmio passou a ser proporcional ao percentual de dias de efetivo exercício no ano-referência. A lógica é a da participação efetiva na busca pela produtividade. Caso o servidor tenha se afastado por qualquer motivo, esse período não é contabilizado para fins do pagamento.

\subsection{Resultados da nova sistemática de premiação}

Como consequência da nova lógica de premiação por produtividade, houve rápida expansão da assinatura de acordos de resultado, relacionada à facilidade de viabilizar o pagamento do prêmio, em caso de resultados positivos. Houve súbito interesse de boa parte das instituições em fazer o processo de planejamento/alinhamento estratégico prévio necessário à assinatura do acordo de resultados, conforme pode ser visto na Tabela 1.

A Tabela 1 mostra que a facilidade e a disponibilidade de recursos para a premiação explicam somente parte dessa expansão. É fundamental destacar também que houve uma decisão de governo de estender essa lógica para todo o Estado. Se um dirigente optasse por não celebrar o acordo, ele estaria indo contra uma lógica que permeava todo o governo, deixando seus servidores de fora da possibilidade de premiação e passando, assim, a ter dificuldades de sustentar-se politicamente. Com a universalização da contratualização de resultados, o número de servidores que participam do programa de remuneração variável cresceu rapidamente e, em 2008, a experiência mineira tornouse o mais abrangente sistema de remuneração variável da administração pública no País.

Em 2009, pela primeira vez, houve a apuração de nota por cada uma das cerca de 4.739 equipes (unidades gerenciais). O processo de avaliação foi mais complexo e teve a participação de 280 pessoas, durante mais de 25 dias de atividades nas reuniões das comissões de acompanhamento e avaliação. Como a legislação não exige o pagamento do prêmio, a incerteza que envolve a premiação também auxilia no descolamento de uma lógica do direito para uma lógica de premiação eventual.

\section{ANÁLISE DO MODELO MINEIRO COMPARADO A EXPERIÊNCIAS INTERNACIONAIS}

Retomando a questão (em quais aspectos o modelo implantado em Minas Gerais se aproxima das experiências internacionais de remuneração variável no setor público?), conclui-se que, do ponto de vista do design, o modelo mineiro mostra-se próximo às boas práticas e às tendências identificadas em experiências internacionais.

Em primeiro lugar, trata-se de um sistema universal e parametrizado em resultados por equipe, aderente à tendência internacional e coerente com a maior eficácia observada nessas características. O formato de premiação é o bônus, que se mostra como opção crescente nas experiências. O volume financeiro da remuneração variável, pago anualmente, equivale a cerca de $7 \%$ da remuneração mensal, caso fosse recebido mensalmente, sendo compatível com o percentual da maioria das experiências. O período avaliatório do caso mineiro é de um ano, o mesmo da maioria dos programas estudados.

Um aspecto peculiar na experiência mineira é seu fundamento exclusivo em resultados, enquanto boa parte das experiências internacionais insere outros elementos relativos a habilidades/competências dos servidores. No governo mineiro, a avaliação de desempenho individual (ADI) é um instrumento à parte, e seu resultado não tem impacto no valor da premiação por produtividade.

Tabela 1: Abrangência do acordo de resultados e do prêmio por produtividade em Minas Gerais

\begin{tabular}{lrrrrrr}
\hline Ano & $\mathbf{2 0 0 4}$ & $\mathbf{2 0 0 5}$ & $\mathbf{2 0 0 6}$ & $\mathbf{2 0 0 7}$ & $\mathbf{2 0 0 8}$ & $\mathbf{2 0 0 9}$ \\
\hline Percentual de órgãos/entidades com acordos vigentes & $10 \%$ & $22 \%$ & $34 \%$ & $84 \%$ & $89 \%$ & $94 \%$ \\
\hline Número de servidores premiados & 5.002 & 5.855 & 14.119 & 10.190 & 302.291 & 298.000 \\
\hline Valor total da premiação (em milhões de reais) & 34,3 & 56,8 & 36,3 & 75,1 & 386,6 & 318,0 \\
\hline
\end{tabular}

Fonte: dados da pesquisa (2009) e Secretaria de Estado de Planejamento e Gestão (Seplag). 
Outro aspecto relevante diz respeito à relação entre o sistema de remuneração variável mineiro e outras medidas de modernização da gestão. Cabe, aqui, retomar o argumento de Pacheco (2009), segundo o qual um problema frequente no Brasil seria adoção isolada de programas de remuneração variável em relação a outras medidas reformadoras. Como explicitado na terceira seção e ainda de acordo com as análises de Corrêa (2007), Silveira (2008) e Lemos (2009), a experiência de Minas Gerais se insere no contexto do choque de gestão, em que uma série de medidas de melhoria da gestão pública foi implementada concomitantemente. Percebe-se que a remuneração variável é uma ferramenta acessória e indutora da estratégia, mostrando-se como instrumento que potencializa outras ferramentas de gestão implementadas no Estado, como o gerenciamento de projetos. Talvez o aspecto único do caso mineiro seja a intensidade da integração entre as ferramentas de gestão implementadas e a capacidade delas de potencializarem-se e fortalecerem-se mutuamente.

A implementação de um sistema universal para os servidores públicos implica dois riscos fundados nas lições descritas por Perry, Engbers \& Jun (2009). O primeiro é a implementação de um programa de PRP em todos os setores, mesmo naqueles em que a literatura relata baixo grau de eficácia, como o financeiro. Assim, o modelo mineiro seria, naturalmente, mais eficaz em certos setores e menos em outros. O segundo e mais crítico é o risco de questionamento da sociedade diante do gasto de mais de $R \$ 300$ milhões por ano para premiar os servidores públicos. Nesse ponto, cabe destacar a capacidade do governador do Estado de colocar o tema da gestão pública na agenda estadual e nacional, e de sustentar politicamente tais medidas.

Em relação ao fato de que os programas de PRP não têm, em regra, gerado motivação adicional nos empregados - lição 1, apontada por Perry, Engbers \& Jun (2009) -, cabe avaliar, por meio de pesquisas específicas, qual a influência da premiação, como incentivo ao esforço adicional, em relação à produtividade sem premiação. No caso mineiro, notam-se medidas para fortalecer a percepção entre desempenho e premiação, como a definição de metas por equipe e a remuneração diretamente proporcional ao resultado da equipe. Em estudo recente realizado por Rodrigues (2009), constatou-se, por meio de um survey, que as metas e as recompensas têm efeitos positivos sobre a motivação dos funcionários do setor público em Minas Gerais. Além disso, o estudo concluiu que a gestão com metas e recompensas tem ótimo potencial para elevar a motivação dos servidores públicos pesquisados.

Outro ponto central refere-se à lição 3, levantada por Perry, Engbers \& Jun (2009): a percepção dos servidores sobre o modelo é diretamente fundada no seu grau de transparência e confiabilidade. Em função das características do sistema de avaliação do acordo de resultados em Minas Gerais (existência de comissão avaliadora com representante dos servidores, integralidade dos critérios e relatórios de avaliação publicados na Internet), é notado que a percepção do sistema como sendo injusto é pouco comum. Esse fato tende a gerar efeitos positivos em relação à efetividade da premiação.

Relacionando-se as lições 1 e 3 de Perry, Engbers \& Jun (2009) com as conclusões do estudo de Rodrigues (2009), pode-se acreditar que, na amostra coletada por este último, existiram condições para a premiação influenciar positivamente o alcance das metas e para melhorar a motivação dos funcionários no ambiente criado pelo programa.

Há diversas críticas ao modelo expressas por dirigentes de órgãos e servidores, que, muitas vezes, questionam a qualidade das metas e o processo de pactuação, muitas vezes tachado de impositivo e autoritário. Outra crítica é a pactuação de metasmeio, procedimentais, não focadas nos fins de cada unidade gerencial. Há a necessidade de pesquisas específicas para verificar a pertinência e o alcance dessas críticas.

Chama atenção a crítica de Athayde (2009), que analisou os resultados das notas da avaliação das equipes e verificou que existe baixa correlação entre os resultados alcançados na primeira e na segunda etapas do acordo de resultados. O grau de sucesso nos outcomes e nos projetos estruturadores não encontra nenhuma correlação entre as notas obtidas pelas equipes (ATHAYDE, 2009). Esse desalinhamento talvez indique que a definição de metas por equipe pode estar sendo capturada pela intenção de premiar o máximo possível, o que seria uma consequência da vinculação da remuneração variável à lógica da contratualização. Já que o acordante (quem define 
as metas) é o dirigente máximo da organização, ele pode intencionalmente favorecer seus colaboradores, utilizando o acordo de resultados e o prêmio por produtividade como meio para o aumento da remuneração. Esse aspecto pode indicar importante risco para o modelo mineiro.

O fato de tal modelo ter nascido e funcionado, durante quatro anos, como um sistema de contratualização de resultados possibilitou a consolidação do modo de mensuração de resultados antes do surgimento da remuneração variável como política universal. Esse fato certamente contribuiu para fortalecer o sistema avaliatório, reduzindo as chances de que ele tenha vícios típicos de sistemas que, já em seu início, são contaminados pela permissividade gerada pelas pressões de buscar uma nota - e uma remuneração - sempre maior.

Porém, a efetividade do modelo apresentado dependerá da capacidade de seus implementadores em enfrentar os riscos de que a definição de metas por equipe seja fortemente conservadora, fazendo com que o processo de contratualização seja apenas uma forma de legitimar um 14º salário.

\section{CONSIDERAÇÕES FINAIS}

Ao se investigar em quais aspectos o modelo de remuneração variável no setor público implantado em Minas Gerais se relaciona com as experiências internacionais, foi possível concluir que, do ponto de vista do design, ele se aproxima dessas práticas em quase todos os aspectos, exceto por ser parametrizado exclusivamente em resultados. Dentre os principais dilemas enfrentados pelo modelo mineiro, destaca-se o risco da universalização do prêmio por produtividade, que pode induzir um comportamento oportunista e conservador na definição de metas, contribuindo negativamente para sua efetividade.

Conforme concluíram Perry, Engbers \& Jun (2009), os estudos em todo o mundo mostram que, via de regra, programas de remuneração variável não são capazes de gerar, por si, aumento da produtividade dos empregados. Entretanto, num ambiente adequado, as transformações necessárias para sua implementação são indutoras da melhoria do desempenho das instituições, na medida em que geram efeitos derivados positivos. Deve-se avaliar se essas condições adequadas estão presentes no caso mineiro e, a partir delas, o impacto da premiação verificado quando analisados os resultados.

Ao se realizar uma pesquisa qualitativa exploratória focada na observação participante, assumiu-se a limitação de que ela não seria conclusiva do ponto de vista metodológico. Nesse sentido, fica a sugestão de complementá-la oportunamente, realizando um estudo quantitativo conclusivo. É necessário reafirmar a premissa metodológica de que o modelo mineiro foi descrito neste artigo sob a ótica de quem o concebeu e o implementou. Há que se verificar, com novas pesquisas, até que ponto o modelo aqui detalhado opera satisfatoriamente nos órgãos e entidades e, ainda, qual a visão dos servidores e dirigentes acerca de seu funcionamento. Cabe ainda sugerir que seja avaliado se a experiência de remuneração variável em Minas Gerais é positiva em relação ao seu custo.

A conjuntura política atual em Minas Gerais reúne um conjunto de condições favoráveis para implementar políticas de gestão pública que dificilmente se repetirá. Nesse sentido, a atual experiência mineira se tornará, provavelmente, referência nacional em contratualização de resultados e remuneração variável. 


\section{REFERÊNCIAS}

Athayde, Thiago Hollerbach. 2009. Avaliação do modelo mineiro de contratualização: uma perspectiva do alinhamento estratégico. Monografia (Graduação em Economia) - Faculdade de Ciências Econômicas da Universidade Federal de Minas Gerais. Belo Horizonte: Face/UFMG.

BrasIL. Ministério de Administração e Reforma do Estado - Mare. Plano Diretor da Reforma Administrativa do Aparelho do Estado. Brasília: Mare, 1995.

CorrêA, Izabela Moreira. Planejamento estratégico e gestão pública por resultados no processo de reforma administrativa do Estado de Minas Gerais. Revista de Administração Pública - RAP, v. 41 n. 3, p. 487-504, Rio de Janeiro, maio/junho, 2007

Jann, Werner \& Reichard, Christoph. Melhores práticas na modernização do Estado. Revista do Serviço Público, v. 53, n. 3, p. 31-35, Brasília, julho/ setembro, 2002.

LAWLER III, Edward. E. Rewarding excellence: paying strategies for the new economy. San Francisco: Jossey-Brass, 2000.

Lemos, Carolina S. 2009. Gestão pública orientada para resultados: avaliando o caso de Minas Gerais. Dissertação (Mestrado em Administração Pública) - Escola Brasileira de Administração Pública e de Empresas da Fundação Getulio Vargas, Rio de Janeiro: Ebape-FGV.

MARSDEN, David. The role of performance related pay in renegotiating the 'Effort Bargain': the case of the British Public Service. Industrial and Labor Relations Review, v. 57, n. 3, article 2, p. 350-370, Ithaca, 2004.

Minas Gerals. Plano Mineiro de Desenvolvimento Integrado - PMDI 2007-2023. Belo Horizonte, 2007. Disponível em: <http://www.planejamento. mg.gov.br>. Acesso em: 10 de setembro de 2009.
O’Reilly III, Charles A. \& Pfeffer, Jeffrey. Unlocking the hidden value in organization. Employment Relations Today, v. 27, n. 2, p. 63-80, New York, Summer, 2000.

Organisation de Coopération et de Développement ÉCONOMIQUeS - OCDE. Paying for performance: policies for government employees. Paris: OECD Publishing, 2005.

Pacheco, Regina Sílvia V. Mensuração de desempenho no setor público: os termos de um debate. In: II Congresso Consad de Gestão Pública. Anais... Brasília: Consad, 2009.

Perry, James L.; Engbers, Trent A. \& Jun, So Yun. Back to the future? Performance-related pay, empirical research, and the perils of persistence. Public Administration Review, v. 69, n.1, p. 1-31, Washington, January/February, 2009.

Pfeffer, Jeffrey. Put the spot light on personnel. Security Management, v. 43, n. 8, p. 31-35, Arlington, August, 1999.

Pfeffer, Jeffrey \& VeIGA, John F. Putting people first for organizational success. The Academy of Management Executive, Ada, v. 13, n. 2, p. 3748, May, 1999.

Rodrigues, Weslei Alves. 2009. A influência das metas e recompensas na motivação. Dissertação (Mestrado em Administração) - Universidade Fundação Mineira de Educação e Cultura. Belo Horizonte: Fumec.

Silveira, Mauro César \& Borges, Thiago Bernardo. A construção do alinhamento estratégico no Estado de Minas Gerais. II Encontro de AdminISTRAÇão Pública e Governança - EnAPG. Anais... Salvador: Anpad, 2008.

VilhenA, Renata et al. (Orgs.). O choque de gestão em Minas Gerais: políticas de gestão pública para o desenvolvimento. Belo Horizonte: UFMG, 2006. 